\title{
Highlighting the importance of "popular epidemiology"
}

\section{Gareth Morgan}

Common sense dictates that communities that feel most understood in terms of daily experience will also be the ones most receptive to a health improvement policy.

re Wales, the community councils represent the lowest tier of local government. From personal service experience in one of the councils it seems that day to day, people are concerned with matters such as dog fouling, small scale vandalism, litter, and car parking facilities. These community concerns have an impact upon health and wellbeing in a variety of ways and might be appropriately termed "popular epidemiology".

Anecdotally, it seems that family doctors working in the Welsh mining communities tended to be very aware of the importance of "popular epidemiology". This awareness may have been related to several factors including high social capital and general openness between people. It therefore seems that "popular epidemiology" has less prominence now than it had historically and this is probably to the detriment of public health practice.

Does the concept of "popular epidemiology" fit into a theoretical scientific paradigm? Perhaps not as it is dynamic and highly dependent on virtually every factor imaginable. While scientific paradigms tend to focus on specific problems depending on the method used, "popular epidemiology" integrates multiple factors through life experience. Therefore, it relates strongly to perceptions, values, and belief systems and these can be variable.

So while "popular epidemiology" may seem to be a nebulous concept, it does have a potential to support public health practice. Indeed, common sense dictates that communities that feel most understood in terms of daily experience will also be the ones most receptive to a health improvement policy.

Over the past 40 years, the Archie Cochrane legacy has done much to further the cause of the evidence based movement and the benefits of the legacy have been enormous. Yet there has been no emphasis on "popular epidemiology". This paper highlights the importance of "popular epidemiology" so that it may be considered with the mainstream public health agenda.

$J$ Epidemiol Community Health 2005;59:254. doi: 10.1136/jech.2004.021279

Correspondence to: Mr G Morgan, 41 Ffordd Beck, Gowerton, Swansea SA4 3GE, Wales; morgan@fforrdbeck.fsnet.co.uk

Funding: none.

Conflicts of interest: none declared.

The author is a Community Councillor, Gowerton, Wales have used data collected within administrative boundaries. ${ }^{216}$ Studies of large areas, such as UK regions (with hundreds of thousands of residents), are difficult to interpret. ${ }^{17-19}$ Recent studies have examined effects over smaller areas, ranging from Amsterdam boroughs (average population 33000 ), postcode sectors and neighbourhoods (average population $8000-10000),{ }^{19}$ to UK electoral wards (average population 5500), ${ }^{3}{ }^{7}$ and US census tracts (average population 4000). ${ }^{9}$ Effect sizes at these levels are small and rarely statistically significant-percentage of variance in symptoms of anxiety and depression ranges from $0.5 \%$ to $4 \%$ before adjusting for residents' characteristics, to less than $1 \%$ after doing so.

Wards may be too large and heterogeneous to detect contextual effect, and variance in CMD may be greater over smaller areas. ${ }^{20}$ The significance of this modest trend remains unclear, and there have been few studies of very small areas. A study using postcode 
units (average population 150) in South Wales (Glyn Lewis, personal communication) found results that differed little from those across UK electoral wards. "Neighbourhood" remains notoriously difficult to define. ${ }^{21}$ While some studies have defined neighbourhoods using natural boundaries, ${ }^{22-24}$ others have used "neighbourhood" to describe administrative units such as US census tracts. ${ }^{25-27}$ Other studies avoid this altogether, asking survey respondents to make implicit judgements about boundaries of "their neighbourhood" or "their area" $^{28}$

One notable finding is substantial between household variation in rates of CMD in Britain, although most studies overlook this as a discrete level. ${ }^{35}{ }^{14}$ In a national study, over $10 \%$ of variance in score on the 12 item general health questionnaire occurred at household level. This finding was not changed, even by adjusting for characteristics of individuals (including marital status, ethnicity, education, employment status, financial strain, and the number of current physical health problems), households (income, car access, housing tenure, social class, composition), or wards. ${ }^{4}$ This finding remains unexplained, but could be attributable to exposures operating at a spatial level between ward and household.

\section{ARE WE STUDYING THE WRONG EXPOSURES?}

As most studies are secondary analyses, ${ }^{2}$ places are often characterised using census based aggregate measures of the population composition. The most commonly used measures are those reflecting prevailing socioeconomic circumstances, such as (un)employment, housing tenure, and proportion of single adult households, either singly or in combination, 56910 or income inequality. ${ }^{10 a}$ None of these is associated with the prevalence of CMD to a statistically significant degree after adjusting for individual characteristics.

"Contextual" measures reflect characteristics of places rather than residents. The latter are rare in the literature, notable exceptions being studies with independent observations of the built environment. ${ }^{24} 26$ The distinction from compositional indices may not be clear cut, ${ }^{2}$ as variables measured at the individual level (for example, educational attainment, employment) may be influenced by area characteristics (for example, quality of local schools, job opportunities, public transport). Unfortunately, the dearth of validated contextual measures precludes empirical investigation of this hypothesis. The work of MacIntyre and her colleagues, who are developing measures of place based on needs, represents a major empirical advance. ${ }^{28}$

Summary statistics from surveys of residents' perceptions of their local environment $^{25} 29$ are one alternative to census based descriptors. This approach is common in social capital research, which has been criticised theoretically and empirically (Health Development Agency, 2004). Another approach has been to classify small areas according to a particular characteristic. Several UK studies have found a higher prevalence of CMD among those living in "urban" (compared with "rural" or "suburban") areas. ${ }^{30-33}$ Suicide rates are also higher in urban than rural areas of Britain, ${ }^{34}$ although this gradient may be falling. ${ }^{35}$ In Sweden, a study of the entire population aged 25-64 found a statistically significant linear association between increasing population density and rates of first admission for depression. ${ }^{15}$ By contrast, studies in New Zealand, ${ }^{36}$ USA, ${ }^{37}$ Scandinavia, ${ }^{33}$ and Canada $^{38}$ found no evidence of statistically significant urban-rural differences in CMD prevalence. These inconsistencies may be partly methodological, especially given varying definitions of "urban" and "rural". Cross national comparisons are difficult given historic, socioeconomic, and ethnic differences in rural and urban populations in different countries. ${ }^{39}$

Population density (for example, Sundquist et $a l^{15}$ and Wang ${ }^{38}$ ) may fail to capture aspects such as geographical remoteness, ${ }^{35}$ and some researchers have resorted to subjective or impressionistic definitions. ${ }^{31}{ }^{33}$ The assumption that rural residents are less deprived and healthier than their urban counterparts has also been challenged statistically. Rural wards (in the UK) are smaller, and have greater internal (between individual) variability with respect to deprivation than urban wards. While rural areas are more internally heterogeneous, even over areas smaller than wards, there is less variation in deprivation between rural areas than their urban counterparts. ${ }^{40}$ Associations between area level socioeconomic deprivation and worse health emerge for rural areas when wards are aggregated to approximate the greater size of urban wards. ${ }^{40}$

\section{ARE WE STUDYING THE WRONG OUTCOMES?}

Reliance on secondary analysis and the need for large samples means that most studies use self report measures of anxiety and depression symptoms. In studies of individual socioeconomic status and CMD, larger effect sizes are observed in studies that use standardised clinical interviews. ${ }^{41}{ }^{42}$ The same may also be true for place and CMD. ${ }^{14}$ Standardised clinical interviews might capture more severe episodes of disorder, and be less prone to "false positives" arising from mild or transient disturbance, or physical ill health. However, traditional objections to findings not based on clinical diagnostic categories are lessened by evidence that CMD are most validly represented as a single dimension encompassing comorbid anxiety and depression. ${ }^{43-45}$ One important problem is that measures such as the general health questionnaire may be prone to socioeconomic response bias, with those in lower occupational grades underreporting symptoms. ${ }^{46}$

The dearth of prospective studies is striking. This is especially problematic in studies of chronic or recurrent disorders such as anxiety and depression, because cross sectional studies may conceal associations between risk factors and either the onset or outcome of episodes of disorder. Evidence that socioeconomic adversity is associated with longer episodes of the CMD but not episode onset ${ }^{47-49}$ suggests that episode duration should be longer in areas with the highest levels of socioeconomic deprivation.

ARE OUR MODELS MISSPECIFIED? Substantial variance in CMD at household level is little changed by controlling for a host of household and individual level characteristics. As this variance remains unexplained, our models remain incomplete. The findings at household level are consistent with spousal similarity in depressive symptoms, ${ }^{50}$ and intra-household processes warrant scrutiny.

The effects of place may also vary with individual and households characteristics. ${ }^{2}$ This is reflected in an urban excess of CMD only among those who were economically inactive, ${ }^{51}$ variation in suicide rates with area level and individual socioeconomic factors, particularly unemployment, ${ }^{52} 53$ and interaction between ethnicity and urban/rural location in the association with depressive symptoms among those living in poverty in the USA. ${ }^{54}$ Thus, place may only affect those with specific vulnerabilities. ${ }^{13}$

\section{ARE WE ASKING THE WRONG QUESTIONS?}

It is inconceivable that the effects of place on mental health are instantaneous, and cross sectional studies are arguably the least informative. The most potent risk factors may be those operating during childhood. ${ }^{55}$ Educational and employment opportunities vary considerably between places. Adjusting for the socioeconomic characteristics of residents overlooks the fact that these are likely to be determined in part by where they live (or have lived). We know that deprived people live in deprived places 
and are less healthy than those living in affluent areas. We need to know much more about residential mobility, who moves between areas, why they move, and what effect this has on their health. The health effects of residential mobility (or lack thereof)-like those of place more generally-may vary with individual circumstances, including health. ${ }^{56}$

\section{CONCLUSIONS}

There is little cross sectional variance in the prevalence of the CMD between areas with populations of 5000-8000 in the UK, Netherlands, and USA. Such areas may be too large to observe effects at a very localised level. Substantial variance at the household level may provide partial support for this view.

Place may still matter-but not in ways that have been studied to date. Anxiety and depression are important public health problems in their own right, and their prevalence is not declining. These conditions are also associated with mortality and physical morbidity, particularly cardiovascular disease. As acute and chronic environmental stressors are potent drivers of onset and outcome, living in places with fewer amenities, or where personal safety is less secure, might lead to higher rates of psychiatric morbidity. Alternatively, risk may be confined to those with specific vulnerabilities, or those exposed to such environments at developmentally critical times. If this is so, modifying the physical or social environments could lead to substantial reductions in rates of the most common mental disorders.

Most existing studies are limited by reliance on secondary and cross sectional data sources, administrative rather than natural geographical boundaries, and compositional measures of place. There is a need for more hypothesis driven primary research, and more measures of place that do not rely on residents' characteristics or perceptions of their locale, and that describe places at different spatial scales. Research needs to be longitudinal, based on population samples large enough to test hypotheses about interactions between people and places, and inclusive of household level exposures and outcomes.

$J$ Epidemiol Community Health 2005; 59:254-257

doi: 10.1136/jech.2004.027797

Correspondence to: Professor S Weich, Division of Health in the Community, Warwick Medical School, Medical School Building, University of Warwick, Coventry CV4 7ÁL, UK; s.weich@warwick.ac.uk

\section{REFERENCES}

1 Dorling D. Anecdote is the singular of data. Environment and Planning A 2001;33:1335-40.
2 Macintyre S, Ellaway A, Cummins S. Place effects on health: how can we conceptualise, operationalise and measure them? Soc Sci Med 2002;55:125-39.

3 McCulloch A. Ward-level deprivation and individual social and economic outcomes in the British household panel study. Environment and Planning A 2001;33:667-84.

4 Weich S, Holt G, Twigg L, Lewis G, et al. Geographical variation in the prevalence of common mental disorders in Britain: a multilevel investigation. Am J Epidemiol 2003;157:730-7.

5 Wainwright NWJ, Surtees PG. Places, people, and their physical and mental functional health J Epidemiol Community Health 2003;58:333-9.

6 Reijneveld SA, Schene AH. Higher prevalence of mental disorders in socioeconomically deprived urban areas in the Netherlands: community or personal disadvantage? J Epidemiol Community Health 1998;52:2-7.

7 Wainwright NWJ, Surtees PG. Area and individual circumstances and mood disorder prevalence. Br J Psychiatry 2004; 185:227-32.

8 Pickett KE, Pearl M. Multilevel analyses of neighbourhood socioeconomic context and health outcomes: a critical review. J Epidemiol Community Health 2001;55:111-22.

9 Ross CE. Neighborhood disadvantage and adult depression. J Health Soc Behav 2000;41:177-87.

10 Henderson C, Diez Roux AV, Jacobs Jr DR, et al. Neighbourhood characteristics, individual level socioeconomic factors, and depressive symptoms in young adults: the CARDIA study. J Epidemiol Community Health 2005;59:322-8.

10a Weich S, Lewis E, Jenkins SP. Income inequality and the prevalence of common mental disorders in Britain. Br J Psychiatry 2001;178:222-7.

11 van Os J, Driessen G, Gunther N, et al. Neighbourhood variation in incidence of schizophrenia. Br J Psychiatry 2000;176:243-8.

12 Boydell J, van Os J, McKenzie K, et al. Incidence of schizophrenia in ethnic minorities in London: ecological study into interactions with the environment. $B M J$ 2001:323:1336-40.

13 van Os J. Does the urban environment cause psychosis? Br J Psychiatry 2004;184:287-8.

14 Silver E, Mulvey EP, Swanson JW. Neighborhood structural characteristcs and mental disorder: Faris and Dunham revisited. Soc Sci Med 2002:55: 1457-70.

15 Sundquist K, Frank G, Sundquist J. Urbanisation and incidence of psychosis and depression. Follow-up of 4.4 million women and men in Sweden. Br J Psychiatry 2004; 184:293-8.

16 Mitchell R. Multilevel modeling might not be the answer. Environment and Planning $A$ 2001;33:1357-60

17 Lewis G, Booth M. Regional differences in mental health in Great Britain. J Epidemiol Community Health 1992;46:608-11.

18 Duncan C, Jones K, Moon G. Psychiatric morbidity: a multilevel approach to regional variation in the UK. J Epidemiol Community Health 1995;49:290-5.

19 Skapinakis P, Lewis E, Araya R, et al. Mental health inequalities in Wales, UK: a multilevel investigation of the affect of area deprivation. $\mathrm{Br} J$ Psychiatry (in press).

20 Reijneveld SA, Verheij RA, de Bakker DH. The impact of area deprivation on differences in health: does the choice of the geographical classification matter? J Epidemiol Community Health 2000:54:306-13.

21 Burrows R, Bradshaw J. Evidence-based policies and practice. Environment and Planning $A$ 2001;33:1345-8.

22 Birtchnell J, Masters N, Deahl M. Depression and the physical environment: a study of young married women on a London housing estate. Br J Psychiatry 1988; 153:56-64.

23 Halpern D. Mental health and the built environment. London: Taylor and Francis, 1995.

24 Weich S, Blanchard M, Prince M, et al. Mental health and the built environment: a cross-sectional survey of individual and contextual risk factors for depression. Br J Psychiatry 2002;180:428-33.

25 Sampson RJ, Raudenbush SW, Earls F. Neighborhoods and violent crime: a multilevel study of collective efficacy. Science 1997:277:918-24.
26 Cohen D, Spear S, Scribner R, et al. "Broken windows" and the risk of gonorrhea. Am J Public Health 2000;90:230-6.

27 Hembree C, Galea S, Ahern J, et al. The urban built environment and overdose mortality in $\mathrm{New}$ York City neighborhoods. Health and Place 2005; 11:147-56.

28 Maclntyre S, Ellaway A, Hiscock R, et al. What features of the home and the area might help to explain the observed relationships between housing tenure and health? Evidence from the west of Scotland. Health and Place 2003;9:207-18.

29 Cohen DA, Farley TA, Mason K. Why is poverty unhealthy? Social and physical mediators. Soc Sci Med 2003;57:1631-41

30 Lewis G, Booth $M$. Are cities bad for your mental health? Psychol Med 1994;24:913-16.

31 Meltzer H, Gill B, Petticrew M. The prevalence of psychiatric morbidity among adults aged 16-64 living in private households in Great Britain. London: HMSO, 1995.

32 Paykel ES, Abbott R, Jenkins $R$, et al. Urban-rural mental health differences in Great Britain: findings from the national morbidity survey. Psychol Med 2000;30:269-80.

33 Lehtinen V, Michalak E, Wilkinson C, et al. Urban-rural differences in the occurrence of female depressive disorder in Europe. Soc Psychiatry Psychiatr Epidemiol 2003;38:283-9.

34 Saunderson T, Haynes R, Langford IH. Urbanrural variations in suicides and undetermined deaths in England and Wales. J Public Health Med 1998;20:261-7

35 Middleton N, Gunnell D, Frankel S, et al. Urbanrural differences in suicide trands in young adults: England and Wales, 1981-1998. Soc Sci Med 2003;57:1183-94.

36 Romans-Clarkson SE, Walton VA, Herbison GP, et al. Psychiatric morbidity among women in urban and rural New Zealand: psycho-socia correlates. Br J Psychiatry 1990;156:84-91.

37 Blazer D, George LK, Landerman R, et al. Psychiatric disorders: a rural/urban comparison. Arch Gen Psychiatry 1985:42:651-6.

38 Wang JL. Rural-urban differences in the prevalence of depression and associated impairment. Soc Psychiatry Psychiatr Epidemiol 2004;39:19-25

39 Costello EJ, Keeler GP, Angold A. Poverty, race/ ethnicity, and psychiatric disorder: a study of rural children. Am J Public Health 2001;91:1494-8.

40 Haynes R, Gale S. Deprivation and poor health in rural areas: inequalities hidden by averages. Health and Place 2000;6:275-85.

41 Blazer DG, Kessler RC, McGonagle KA, et al. The prevalence and distribution of major depression in a national community sample: the national comorbidity survey. Am J Psychiatry 1994;151:979-86.

42 Singleton N, Bumpstead R, O'Brien $M$, et al. Psychiatric morbidity among adults living in private households, 2000. London: TSO, 2001.

43 Krueger RF. The structure of the common menta disorders. Arch Gen Psychiatry 1999;56:921-6.

44 Vollebergh WAM, ledema J, Bijl RV, et al. The structure and stability of common menta disorders. Arch Gen Psychiatry 2001;58:597-603

45 Kendell R, Jablensky A. Distinguishing between the validity and utility of psychiatric diagnoses. Am J Psychiatry 2003;160:4-12.

46 Stansfeld SA, North FM, White I, et al. Work characteristics and psychiatric disorder in civil servants in London. J Epidemiol Community Health 1995;49:48-53.

47 Weich S, Lewis G. Poverty, unemployment and common mental disorders: population-based cohort study. BMJ 1998;317:115-19.

48 Lorant V, Deliège $\mathrm{D}$, Eaton W, et al. Socioeconomic inequalities in depression: a metaanalysis. Am J Epidemiol 2003:157:98-112.

49 Hauck K, Rice N. A longitudinal analysis of mental health mobility in Britain. Health Econ 2004; 13:981-1001.

50 Dufouil C, Alpérovitch A. Couple similarities for cognitive functions and psychological health. J Clin Epidemiol 2000;53:589-93.

51 Weich S, Twigg L, Holt G, et al. Contextual risk factors for the common mental disorders in 
Britain: a multilevel investigation of the effects of place. J Epidemiol Community Health 2003:57:616-21.

52 Kelly S, Charlton J, Jenkins R. Suicide deaths in England and Wales, 1982-92: the contribution of occupation and geography. Popul Trends 1995;80:16-25.
53 Saunderson TR, Langford IH. A study of the geographical distribution of suicide rates in Eng and and Wales 1989-92 using empirical Bayes estimates. Soc Sci Med 1996:43:489-502.

54 Amato PR, Zuo J. Rural poverty, urban poverty, and psychological well-being. Sociological Quarterly 1992;33:229-40.
55 Gilman SE, Kawachi I, Fitzmaurice GM, et al. Socioeconomic status in childhood and lifetime risk of major depression. Int J Epidemiol 2002;31:359-67.

56 Ross CE, Reynolds JR, Geis KJ. The contingent meaning of neighborhood stability for residents' psychological well-being. Am Sociol Rev 2000;65:581-97.

\section{Population ideals and sample realities - why we still need access to comprehensive information about populations}

\section{Geraldine Barrett, Janet L Peacock}

Public health population research will be rendered impossible if individual consent for all secondary uses of health data becomes the norm.

M uch epidemiological and health services research relies on surveys and Jousilahti et al's paper is a timely reminder to us about the biases caused by participants' nonresponse. Although we all know that non-response is a socially patterned phenomenon, this knowledge is so familiar that it is easy to become complacent-how many of us have ticked the mental boxes of ">70\%" and "information about response biases" as markers of a good quality survey when reading or reviewing a paper? Jousilahti et al's paper is valuable in that it provides data from several national, large scale, well conducted Finnish surveys with high response rates, and it shows the differences in health outcome, in this case mortality, according to responder status. It is sobering to realise that even with an aggregate response rate of $>80 \%$ findings may still be subject to substantial bias.

As if Jousilathi et al's findings were not important enough, with their implications for the conduct and interpretation of population surveys, their study also has wider relevance. Unlike Finland, where studies such as this are possible because of the comprehensive records infrastructure (a national register, permissions for record linkage), other countries, such as the UK, Australia, Canada, and the USA, are moving towards a requirement of individual consent for the use of identifiable medical data in health research. ${ }^{2-4}$ Hence in these countries investigators are experiencing increased difficulties in identifying unbiased samples for cross sectional surveys and cohort and casecontrol studies and in assembling accurate, comprehensive datasets for records based analysis. Published evidence has already shown the hugely detrimental effect of a requirement of individual consent. $^{56}$ However, the regulatory authorities seem unconvinced that bias in data is a legitimate concern and maintain that they are safeguarding the rights of the patient, for example:

"I would have to say that I've heard an argument made and I've heard a lot of anecdotal evidence that not having the full sample somehow badly skews epidemiological research. Not to say it is not out there, but I have not seen the persuasive evidence that this is in fact the case. ${ }^{\prime 7}$

"We have received a number of applications for Section 60 support to cover research studies where it has been argued that it would not be appropriate to seek consent from patients because failure of any patients to agree to participate in the study may bias the research findings. ... It is not sufficient for applicants to simply state that certain groups are less likely to provide consent; we seek evidence to justify such comments. ${ }^{\prime \prime}$

Perhaps this paper will help provide the evidence that bodies such as these seek. If individual consent for all secondary uses of health data becomes the established norm then most public health and health services population based research will be rendered impossible, to the detriment of the health evidence base. To prevent this, the public health community needs to convince those outside the research arena that existing (and recent) uses of identifiable health data are in the public interest.

J Epidemiol Community Health 2005;59:257. doi: 10.1136/jech.2004.028753

\section{Authors' affiliations}

G Barrett, J L Peacock, School of Health Sciences and Social Care, Brunel University, Middlesex, UK

Correspondence to: $\operatorname{Dr} G$ Barrett, School of Health Sciences and Social Care, Brunel University, Osterley Campus, Borough Road, Middlesex TW7 5DU, UK; geraldine.barrett@ brunel.ac.uk

Funding: none.

Competing interests: GB and JLP carry out public health/health services research.

\section{REFERENCES}

1 Jousilahti P, Salomaa V, Kuulasmaa K, et al. Total and cause specific mortality among participants and non-participants of population based health surveys: a comprehensive follow up of 54372 Finnish men and women. J Epidemiol Community Health 2005:59:310-15.

2 Coleman MP, Evans BG, Barrett G. Confidentiality and the public interest in medical research - will we ever get it right? Clin Med 2003;3:219-28.

3 World Medical Association. The World Medical Association declaration on ethical considerations regarding health databases. Ferney-Voltaire, WMA, 2002 (http://www.wma.net/e/policy/ d1.htm).

4 Department of Health. Confidentiality: NHS code of practice. London: DoH, 2003.

5 Angus VC, Entwistle VA, Emslie MJ, et al. The requirement for prior consent to participate on survey response rates: a population-based survey in Grampian. BMC Health Serv Res 2003;3:21 (http://www.biomedcentral.com/1472-6963/ 3/21)

6 Tu JV, Willison DJ, Silver FL, et al. Impracticability of informed consent in the registry of the Canadian Stroke Network. N Engl J Med 2004;350:1414-21.

7 Privacy Commissioner for Canada. In: Canadian Institutes of Health Research. Presentation before the Standing Committee on General Government regarding Ontario Bill 159: an Act respecting personal health information and related matters. OHtowa: CIHR, 2001

8 Patient Information Advisory Group. Annual report. London: Department of Health, 2003, 9 (http://www.advisorybodies.doh.gov.uk/PIAG/ reports.htm). 